\title{
Shaun Fisher (June 8, 1967-January 4, 2015)
}

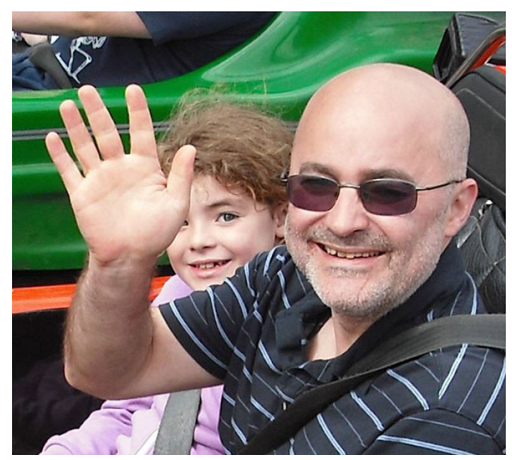

The Editors of the Journal of Low Temperature Physics regret to announce the death of Professor Shaun Fisher who was a member of our Editorial Board. Apart from a period working at CNRS in Grenoble, Shaun has been with Lancaster Department of Physics for the whole of his academic career. Shaun was a consummate experimental physicist and already as a graduate student he was devising experimental techniques which have since been taken up around the world. He will be best remembered for his discovery of quantum turbulence in superfluid helium-3 at microkelvin temperatures (previously thought impossible) and his subsequent studies of quantum turbulence in general. He was also a key part of the team which demonstrated the analogue of cosmic string formation in superfluid helium-3.

The world community and the Lancaster Ultralow Temperature Group have lost a valued colleague and trail-blazer whose innovative and meticulous experimental abilities have inspired and energized his colleagues for many years. Our thoughts go out to Rachel his wife and his two young daughters and all his students, collaborators, and co-workers worldwide who are having to come to terms with this sudden loss.

On behalf of the Editors

George Pickett

Lancaster University 